\title{
The excitation of plasma convection in the high-latitude ionosphere
}

Article

Published Version

Lockwood, M., Cowley, S. W. H. and Freeman, M. P. (1990)

The excitation of plasma convection in the high-latitude ionosphere. Journal of Geophysical Research, 95 (A6). pp. 7961-7972. ISSN 0148-0227 doi: https://doi.org/10.1029/JA095iA06p07961 Available at https://centaur.reading.ac.uk/38864/

It is advisable to refer to the publisher's version if you intend to cite from the work. See Guidance on citing.

Published version at: http://dx.doi.org/10.1029/JA095iA06p07961

To link to this article DOI: http://dx.doi.org/10.1029/JA095iA06p07961

Publisher: American Geophysical Union

All outputs in CentAUR are protected by Intellectual Property Rights law, including copyright law. Copyright and IPR is retained by the creators or other copyright holders. Terms and conditions for use of this material are defined in the End User Agreement.

\section{www.reading.ac.uk/centaur}

\section{CentAUR}

Central Archive at the University of Reading 
Reading's research outputs online 


\title{
The Excitation of Plasma Convection in the High-Latitude Ionosphere
}

\author{
M. LOCKWOOD \\ Rutherford Appleton Laboratory, Chilton, Didcot, Oxon, England \\ S. W. H. COWLEY AND M. P. FREEMAN \\ Blackett Laboratory, Imperial College, London, England
}

\begin{abstract}
Recent observations of ionospheric flows by ground-based radars, in particular by the European Incoherent Scatter (EISCAT) facility using the "Polar" experiment, together with previous analyses of the response of geomagnetic disturbance to variations of the interplanetary magnetic field (IMF), suggest that convection in the high-latitude ionosphere should be considered to be the sum of two intrinsically time-dependent pattems, one driven by solar wind-magnetosphere coupling at the dayside magnetopause, the other by the release of energy in the geomagnetic tail (mainly by dayside and nightside reconnection, respectively). The flows driven by dayside coupling are largest on the dayside, where they usually dominate, are associated with an expanding polar cap area, and are excited and decay on $\sim 10$-min time scales following southward and northward tumings of the IMF, respectively. The latter finding indicates that the production of new open flux at the dayside magnetopause excites magnetospheric and ionospheric flow only for a short interval, $\sim 10 \mathrm{~min}$, such that the flow driven by this source subsequently decays on this time scale unless maintained by the production of more open flux tubes. Correspondingly, the flows excited by the release of energy in the tail, mainly during substorms, are largest on the nightside, are associated with a contracting polar cap boundary, and are excited on $\sim 1$-hour time scales following a southward tum of the IMF. In general, the total ionospheric flow will be the sum of the flows produced by these two sources, such that due to their different response times to changes in the IMF, considerable variations in the flow pattem can occur for a given direction and strength of the IMF. Consequently, the ionospheric electric field cannot generally be regarded as arising from a simple mapping of the solar wind electric field along open flux tubes.
\end{abstract}

\section{INTRODUCTION}

The ionospheric flows which result from coupling between the solar wind and the magnetosphere have been the object of intensive study in recent years (see reviews by Cowley [1986], Lockwood and Cowley [1988], and Lockwood and Freeman [1989]). These flows have been observed directly using polarorbiting spacecraft [Reiff et al., 1981; Wygant et al., 1983; Heelis, 1984; Heppner and Maynard, 1987] and ground-based radars [Willis et al., 1986; Holt et al., 1987; de la Beaujardiere et al., 1987; Clauer and Friis-Christensen 1988], and have also been inferred from ground-based magnetometer data [FriisChristensen et al., 1985; Reiff et al., 1985]. Recent studies have attempted to combine data from these sources to obtain "snapshots" of the flow pattem throughout the high-latitude ionosphere [Heelis et al., 1983; Richmond et al., 1988]. The results of these studies have shown that the high-latitude flow is strongly modulated by the direction and strength of the interplanetary magnetic field (IMF). Indeed, in many of the above studies the flow pattern is taken to be directly parameterized by components of the IMF vector, such that it is implicitly assumed that for given values of these components, a given flow pattem will prevail (see also, for example, the review by Schunk [1988] and references therein). Theoretically, the ionospheric flow in the polar cap has been modeled

Copyright 1990 by the American Geophysical Union.

Paper number 89JA02925.

0148-0227/90/89JA-02925\$05.00 by mapping the interplanetary electric field associated with the solar wind flow along model steady state open magnetospheric field lines into the ionosphere, with the assumption that fieldaligned voltages are small compared with the total voltage imposed across the magnetosphere [Stern, 1973; Lyons, 1985; Rycroft, 1987; Toffoletto and Hill, 1989].

However, it is probable that the magnetosphere may never be adequately described in terms of steady state convection. For steady state circulation to occur, the rate at which the dayside flux tubes are transported into the tail by coupling at the magnetopause to the solar wind flow (e.g., by dayside reconnection) would have to be exactly balanced by the retum of flux from the tail (e.g., resulting from reconnection in the plasma sheet) for an extended period. In general, we should not expect these rates of flux transport to be equal. Indeed, imbalances are inherent in the concepts of the growth and expansion phases of substorms [Russell and McPherron, 1973; Hones, 1979] during which the area of the polar caps grows and shrinks, respectively [e.g., Holzer et al., 1986]. This concept of substorms thus involves periods when flow in the magnetosphere and ionosphere is dominated by dayside reconnection (growth phase) followed by intervals when the flow is dominated by flux return from the tail (expansion phase). In the general, non steady case there will therefore exist no simple relationship between the electric field (and hence flow) on an open flux tube in the ionosphere, and that on the same flux tube in the solar wind. It should be noted that this statement need not imply the presence of a field-aligned voltage along the open flux tubes, but only that the magnetic field configuration is changing with time. 
Russell [1972] sketched schematically the implications of the above discussion for ionospheric convection. More recently, Siscoe and Huang [1985] have quantitatively considered the ionospheric flow which would be set up by reconnection when there is an imbalance between dayside and nightside reconnection rates. They chose to present the flow which would occur in the presence of dayside reconnection but in the complete absence of nightside reconnection. To model this flow, these authors assume that flux is transferred from the closed field line region of the dayside auroral zone into the open field line region (the "polar cap") across a restricted sector of the polar cap boundary near noon (the "merging gap" which maps to the reconnection neutral line at the dayside magnetopause), and that no flux exits the polar cap elsewhere. Consequently, the area of the polar cap must increase with time, such that the rate of change of the polar cap magnetic flux is equal to the voltage along the dayside reconnection neutral line, $\Phi_{D}$, in accordance with Faraday's law. In the absence of significant field-aligned voltages, the voltage along the merging gap, in the rest frame of the gap, is also equal to that along the dayside reconnection line. However, since the merging gap will generally be moving equatorward under these circumstances, the voltage along the gap in the Earth's frame, $\Phi_{D}{ }^{\prime}$, will be smaller than this. Siscoe and Huang assumed that the polar cap boundary remains circular as it expands, in which case $\Phi_{D}{ }^{\prime}=\Phi_{D}(1-f)$, where $f$ is the ratio of the length of the merging gap to the circumference of the polar cap perimeter, which is small if the gap is relatively narrow. In this case $\Phi_{D}{ }^{\prime}$ and $\Phi_{D}$ will not be significantly different. Of course, departures of the polar cap boundary from circularity may certainly occur. In particular, as recently discussed by Freeman and Southwood [1988], the merging gap may initially move rapidly equatorward following a sudden increase in the dayside reconnection rate, in association with an erosion of the dayside magnetosphere. In this case $\Phi_{D}{ }^{\prime}$ will be significantly less than $\Phi_{D}$. However, these conditions cannot persist for prolonged periods in the absence of more general expansions of the polar cap boundary, which will return the configuration toward that assumed by Siscoe and Huang, and $\Phi_{D}{ }^{\prime}$ toward $\Phi_{D}(1-\mathrm{f})$.

The ionospheric flow pattern which Siscoe and Huang derived on the basis of these assumptions is sketched in Figure 1a. In this figure, the thin solid lines indicate plasma streamlines (equipotentials), the dashed lines are merging gaps and the thick solid lines denote the remaining portions of the polar cap boundary which Siscoe and Huang termed "adiaroic" (meaning "not flowing across"). The adiaroic boundaries move with the local plasma flow velocity, as denoted by the large solid arrows. It can be seen that even with completely unbalanced dayside reconnection, a large-scale, twin-vortical convection pattern is driven in the ionosphere, but with high-speed flows generally confined to the dayside. The "region 1 " fieldaligned currents which are associated with this flow pattern, and which flow at the polar cap boundary, also maximize on the dayside (at the ends of the merging gap) and fall continuously to zero at midnight. The role of field-aligned currents in transmitting stress between the magnetosphere and ionosphere has been discussed, for example, by Southwood and Hughes [1983] and Southwood [1987, 1989]. We also note that in subsequent work Moses et al. [1987] have generalized the model developed by Siscoe and Huang to include effects due to spatial variations in the ionospheric conductivity, and the flow effects associated with IMF $B_{Y}$, the latter being incorporated via changes in the orientation of the dayside merging gap.
In Figure $1 b$ we similarly sketch the flow pattern which would be excited by wholly unbalanced reconnection on the nightside, i.e., with no dayside reconnection $\left(\Phi_{D}=0\right)$. The dashed portion of the polar cap boundary again represents the "merging gap" where flux now exits the polar cap, which is connected magnetically to the nightside neutral line. The voltage along the gap, in its rest frame, will then be equal to the voltage along the nightside neutral line, $\Phi_{N}$, (assuming fieldaligned voltages to be small), while in the Earth's frame the voltage $\Phi_{N}^{\prime}$ will be somewhat smaller than this if the gap is moving poleward, as will generally be the case under these conditions, and as assumed in Siscoe and Huang's circular polar cap model. A twin-celled convection pattern will again be generated, but in this case the fastest flows will occur on the nightside, while the polar cap area will decrease with time. Siscoe and Huang argue that the total large-scale convection pattern will, in general, be a superposition of the two basic patterns shown in Figures $1 a$ and $1 b$. Lockwood and Freeman [1989] have given two examples of such patterns, sketched here in Figures $1 c$ and $1 d$. In Figure $1 c$ the dayside voltage $\Phi_{D}$ is taken to be twice the nightside voltage $\Phi_{N}$, whereas in Figure $1 d \Phi_{D}$ is half of $\Phi_{N}$. These are examples of the general case, being neither steady-state, nor showing wholly unbalanced reconnection. Moses et al. [1987] used flow configurations with $\Phi_{D}>\Phi_{N}$ to model satellite flow data during substorm growth phases, while similarly Moses et al. [1989] have modelled the flows observed during substorm expansions by taking $\Phi_{N}>\Phi_{D}$.

Figure 1 thus illustrates how the convection at all locations in the polar cap and auroral oval is influenced by. both dayside and nightside reconnection. However, flows on the dayside will be predominantly controlled by dayside reconnection, whereas flows on the nightside will be mainly controlled by reconnection in the tail. It should be noted that it is implicit in this picture that the flow pattern shown in Figure la should be excited only when dayside reconnection has recently been in progress, and that in Figure $1 b$ only when nightside reconnection has recently been present. The implication is that if both processes cease to occur, then so will the ionospheric flow, at least after some short interval, irrespective of the continued existence of open flux in the polar cap.

The schematics shown in Figure 1 show only the flows driven in the ionosphere by reconnection at the low-latitude dayside magnetopause and in the tail. Two other sources of ionospheric flow are believed to contribute, namely "viscouslike" interactions at the low-latitude magnetopause which transfer momentum from the magnetosheath to closed magnetospheric flux tubes, and reconnection at the high-latitude tail lobe magnetopause which may occur predominantly during periods of northward IMF. These processes generate additional "viscous" and "lobe" cells of ionospheric flow, respectively [Reiff and Burch, 1985], as will now be briefly discussed.

Antisunward flow on closed field lines has been observed directly in the low-latitude boundary layer on the dayside and also on the flanks of the tail [Mitchell et al., 1987; Williams et al., 1985; Mozer, 1984; Richardson et al., 1989]. Such "viscously-driven" flows have also been inferred from the residual antisunward convection observed in the ionosphere when the IMF is northward [Reiff et al., 1981; Cowley, 1982, 1984; Doyle and Burke, 1983; Wygant et al., 1983; Reiff and Luhmann, 1986]. More direct observations of this interaction have been made in the ionosphere by polar-orbiting satellites [Coley et al., 1987] and by ground-based radar [Lockwood et 


\section{Expanding Polar Cap}

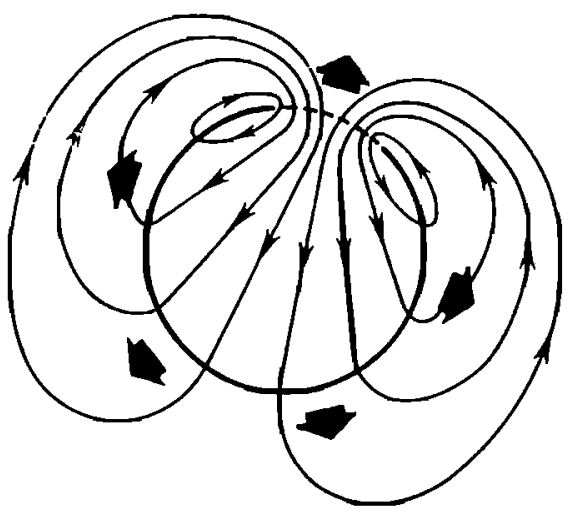

(a) $\Phi_{d}=8 \Delta ; \Phi_{n}=0$

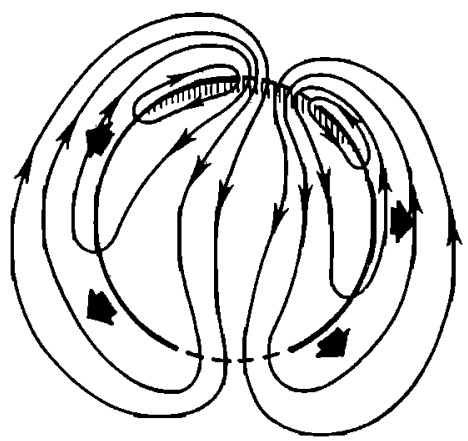

(c) $\Phi_{\mathrm{d}}=8 \Delta ; \Phi_{\mathrm{n}}=4 \Delta$
Contracting Polar Cap

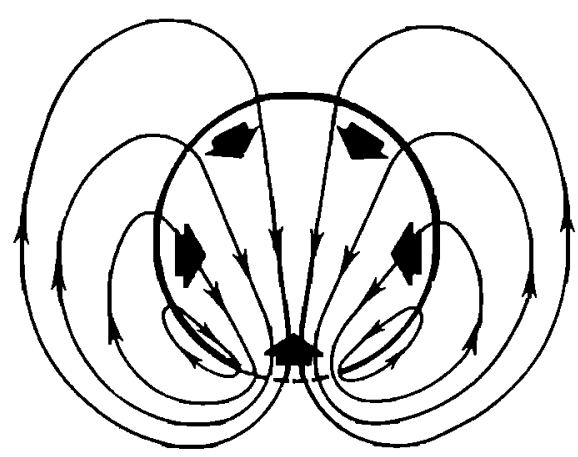

(b) $\Phi_{d}=0 ; \Phi_{n}=8 \Delta$

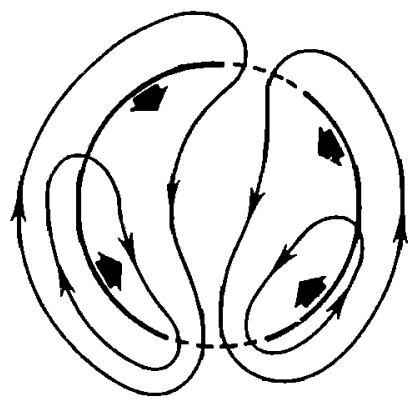

(d) $\Phi_{d}=2 \Delta ; \Phi_{n}=4 \Delta$

\section{$\longrightarrow$ flow equipotential ( $\Delta \mathrm{kV}$ apart) \\ - - - ionospheric projection of reconnection neutral line (merging gap) \\ adiaroic polar cap boundary
boundary motion}

Fig. 1. Sketches of ionospheric convection patterns due to magnetic reconnection at the dayside magnetopause and in the geomagnetic tail. The polar cap boundary is shown as circular for simplicity, the solid lines indicating an "adiaroic" boundary, while the dashed lines are the "merging gaps", i.e., the ionospheric projections of the reconnection neutral lines. Motions of the polar cap boundary are denoted by solid arrows. In the rest frame of the "gaps" the voltage along them is equal to the voltage along respective neutral lines, $\Phi_{D}$ and $\Phi_{N}$ on the dayside and nightside, respectively (assuming field-aligned voltages are small). When $\Phi_{D}>\Phi_{N}$ the polar cap expands, while when $\Phi_{D}<\Phi_{N}$ it contracts. Figures $1 a$ and $1 b$ are for the limiting cases of wholly unbalanced dayside and nightside reconnection respectively, i.e., $\Phi_{D}=8 \Delta$ and $\Phi_{N}$ $=0$ in Figure $1 a$, and $\Phi_{D}=0$ and $\Phi_{N}=8 \Delta$ in Figure $1 b$, where $\Delta$ is an arbitrary unit of voltage, approximately the voltage drop between the streamlines shown in the sketches. Figures $1 c$ and $1 d$ represent more general intermediate cases, with $\Phi_{D}$ $=8 \Delta$ and $\Phi_{N}=4 \Delta$ in Figure $1 c$, such that the polar cap expands, while $\Phi_{D}=2 \Delta$ and $\Phi_{N}=4 \Delta$ in Figure 1d, such that the polar cap contracts. It may be noted that due to boundary motion, in the Earth's frame (as shown in the sketch) the voltages along the "gaps", $\Phi D^{\prime}$ and $\Phi_{N^{\prime}}$ differ moderately from $\Phi_{D}$ and $\Phi_{N}$, such that $\Phi_{D^{\prime}}<\Phi_{D}$ and $\Phi_{N^{\prime}}>\Phi_{N}$ when the polar cap boundary is expanding, while $\Phi_{D^{\prime}}>\Phi_{D}$ and $\Phi_{N}^{\prime}<\Phi_{N}$ when the polar cap boundary is contracting.

al., 1988]. The chief effect of this mechanism is to cause the convection reversal boundary to lie equatorward of the boundary between open and closed field lines.

Observations indicate that as in the case of reconnectiondriven convection there will usually be an imbalance between sunward and antisunward flux transfer rates driven by viscous interaction [Lockwood et al., 1988; Richardson et al., 1989] and hence the principles described by Figure 1 will still apply. To allow for viscous interaction, Figure 1 could be generalized by the inclusion of a more general distribution of potential around the convection reversal boundary. However, because the voltage associated with reconnection is generally considerably larger than that due to viscous-like mechanisms (see the references given above), the simplified potential distributions 
used in Figure 1 (i.e. for purely reconnection-driven flows) give the important features of the behavior of high-latitude convection.

The second source of flow excluded from Figure 1 arises when the IMF is strongly northward and is believed to be caused by reconnection at the high-latitude magnetopause of one or both tail lobes [Dungey, 1963; Russell, 1972; Reiff, 1982]. This process generates sunward flow at high latitudes [Burke et al., 1979; Heelis, 1984; Clauer and Friis-Christensen, 1988]. If a given interplanetary flux tube reconnects with one tail lobe only, then the amount of open flux is unchanged, but an additional circulation ("lobe cell") is introduced into the flow in the corresponding polar cap ionosphere. This can be accommodated in Figure 1 by superposing such circulation within the polar cap on the flows shown in Figures $1 b$ and $1 d$. However, if the same interplanetary flux tube is reconnected at both tail lobes (as in the original suggestion by Dungey), then the amount of open flux, and the polar cap area, is decreased. Russell [1972] pointed out that this second situation is unlikely to occur, except perhaps when the IMF is directed almost due north, but even so could in principle be included in Figure 1 by allowing $\Phi_{D}$ to become negative (i.e., flux exits the polar cap on the dayside). The data to be presented below do not bear upon these two further sources of ionospheric flow, and they will not be further discussed in this paper. They have been introduced here simply to point out that actual geophysical conditions may often be more complex than can be wholly accommodated within the main discussion given in this paper (and, e.g., by Siscoe and Huang [1985]), but that such effects can in principle be incorporated within the general framework, at the expense of further elaboration.

Rather, the purpose of the present paper is to point out that recently published observations of ionospheric flows, obtained in the dayside auroral oval by the EISCAT "Polar" experiment, are very well explained by the two-source flow excitation model illustrated by Figure 1. In particular, these concepts provide an appropriate framework for understanding the observed short (minute) time scales for excitation and decay of dayside flows and their direct modulation by variations in the north-south $\left(B_{z}\right)$ component of the IMF, a topic not explicitly addressed by Siscoe and Huang [1985]. In the following section, we briefly review the evidence concerning the time scales for excitation and decay of auroral convection (and the associated current systems). In section 3 , we present additional evidence for the short decay constant of the dayside flow system, but unlike the observations reviewed in section 2, these European Incoherent Scatter Facility (EISCAT) data are for open field lines within the polar cap. In section 4 we discuss these observatons and their implications for how the solar wind couples to the magnetosphere-ionosphere system, and in section 5 we make some predictions which should be tested to confirm the proposed view of the excitation of ionospheric convection

\section{The Nature of High-LattTude Flows}

Indirect evidence for the bimodal nature of high-latitude convection has, in fact, been available for some considerable time. Geomagnetic disturbances at high latitudes have been divided into two main morphological types, DP-1 and DP-2, where DP-2 is believed to correspond to the currents driven by the "growth phase" twin-vortical flows (and hence by dayside reconnection), while DP-1 is associated with substorms and the nightside "current wedge" (and hence with tail reconnection). Studies have shown that these two current systems respond to changes in the north-south component of the IMF with markedly different response times. Nishida [1968a,b] examined the behavior of the DP-2 current system and found that the current enhancements occurred $7 \pm 1$ min after southward turnings of the IMF had impinged upon the subsolar bow shock. Since the IMF disturbance would have taken at least $5 \mathrm{~min}$ to propagate from the bow shock to the magnetopause, the implied ionospheric response time is very short indeed, no greater than about 2 min. Similarly short response times have also been reported in subsequent case studies [Pellinen et al., 1982; Nishida and Kamide, 1983; McPherron and Manka, 1985; Clauer and Kamide, 1985]. On the other hand, analyses of geomagnetic indices such as $A E$, which are influenced primarily by nightside currents and in particular by the DP-1 substorm current system, have indicated much longer response delays to southward turnings of the IMF. These delays are typically found to be 30-60 min [Schatten and Wilcox, 1967; Arnoldy, 1971; Baker et al., 1981, 1983]. We interpret these times as being the response time of the nightside flow system, set up by the release of tail stress during substorms.

The presence of two separate response time scales has also emerged from studies of the reponse of geomagnetic indices to the IMF using the linear prediction filter technique. Clauer et al. [1981] and Bargatze et al. [1985] found both a short ( 15 $\mathrm{min}$ ) and a longer ( $\sim 60 \mathrm{~min})$ response lag to be present. Correspondingly, a recent study of a limited quantity of flow data obtained in the nightside auroral oval by EISCAT has identified flows which are modulated by the $B_{2}$ component of the IMF with a 15 - to $20-\mathrm{min}$ lag, while other flows appear to be related to substorms [Williams et al., 1989].

The results which we wish to review here in greater detail, however, were obtained by the EISCAT "Polar" experiments conducted during 1984 and 1985 in conjunction with simultaneous measurements of the IMF by the Active Magnetospheric Particle Tracer Explorers (AMPTE-UKS and AMPTE-IRM) satellites [Willis et al., 1986]. Constraints set by satellite tracking meant that simultaneous IMF data were obtained only while the radar was observing dayside flows. In the light of the above discussion, these results should therefore relate mainly to the excitation and decay of flows driven by momentum transfer across the dayside magnetopause, the dominant mechanism for which is reconnection. These combined EISCAT-AMPTE observations allowed the delay in the response of the ionospheric flows to changes in the IMF to be quantified with very low errors, for two reasons. First, the EISCAT Polar experiment allows determination of the flows over a range of latitudes with relatively high time resolution (15 s for line-ofsight velocities, and $2.5 \mathrm{~min}$ for field-perpendicular vectors). Second, the location of the AMPTE spacecraft immediately upstream of the bow shock and close to the Sun-Earth line, allowed the propagation time of IMF variations from the spacecraft to the magnetopause to be determined with low errors.

Initial inspection of these EISCAT-AMPTE data revealed clear and sudden enhancements in sunward flow following southward turnings of the IMF [Rishbeth et al., 1985; Willis et al., 1986]. A cross-correlation analysis of all the data, carried out subsequently by Etemadi et al. [1988], has shown that the response lag of auroral zone flows in the early afternoon sector to changes in the IMF $B_{2}$ component is only $3.9 \pm 2.2 \mathrm{~min}$. Considering that the Alfven wave propagation time from a point on the subsolar magnetopause to its ionospheric footprint 
is nearly $2 \mathrm{~min}$ for the invariant latitudes studied by the Polar experiment [Freeman et al., 1990], this result shows that the dayside coupling process is excited within 1-2 min of a southward magnetosheath field appearing at the magnetopause and that its effects are communicated to the Polar field of view in a further 1-2 min. The first of these conclusions is consistent with in situ spacecraft observations at the magnetopause in that a close correlation has been found between large shears in the magnetic field across the magnetopause and the detection of signatures of reconnection [Rijnbeek et al., 1984; Bercham and Russell, 1984; Paschmann et al., 1986]; any substantial delays in the onset or decay of the coupling process would have tended to destroy this correlation.

For local times away from early aftemoon, however, Etemadi et al. found the response lag was greater, being 10-15 $\mathrm{min}$ near dawn and dusk. These results, determined from a statistical survey of all vector Polar data, have been broadly confirmed using case studies of 15-s line-of-sight velocities for the 20 clear and sudden southward and northward tumings of the IMF which occurred during the same periods of EISCAT-AMPTE observations [Todd et al., 1988a]. The increase in response lag with local time difference from noon has been attributed to a spatial expansion of the new convection pattern, as originally suggested by Lockwood et al. [1986a]. For example, following a southward turning of the IMF, the new enhanced convection pattern expands as the region of newly opened flux expands following the onset (or enhancement) of dayside reconnection. From the variation of response times with MLT, the zonal expansion speed is $\sim 5 \mathrm{~km} \mathrm{~s}^{-1}$ near the centers of the morning and afternoon sectors, falling to below $\sim 1 \mathrm{~km} \mathrm{~s}^{-1}$ near dawn and dusk. The value of $\sim 3 \mathrm{~km} \mathrm{~s}^{-1}$, determined directly at an intermediate MLT by Lockwood et al. [1986a] (from crosscorrelation analysis of the resulting ionospheric ion temperature rises seen at the two observing azimuths of the Polar experiment), is in excellent agreement with the value expected from the response lag variation determined by Etemadi et al. and Todd et al. These expansion speeds are also consistent with the shorter of the response times of $\sim 15 \mathrm{~min}$ determined for nightside currents and flows and are well explained by the expansion model of Lockwood et al. [see Lockwood and Cowley, 1988].

The results on the excitation of ionospheric flow following a southward turning obtained by Rishbeth et al. [1985] and Lockwood et al. [1986a] contain an important implication. The topology of the open magnetosphere ensures that the expanding patch of newly opened flux, generated following the southward turning of the IMF, is formed immediately adjacent to, and equatorward of, the preexisting area of open flux. This "old" polar cap will have been formed by reconnection during intervals before the southward tuming and is thought to be always present, even following periods of prolonged northward IMP. Auroral observations and particle precipitation data indicate that the magnetosphere never becomes fully closed, and certainly there has been no suggestion that the lobes of the geo. magnetic tail ever completely disappear. This being the case, the above EISCAT results show that not all open flux tubes are equally effective in generating ionospheric flow. The newly opened flux formed following the southward turning is observed to generate high-speed flows (several kilometers per second) in a pattern rapidly expanding from noon, whereas the much larger region of old open flux, which must lie immediately poleward of the newly opened flux, generates virtually no flow prior to the southward turning. As a result, the notion that the ionospheric flow in the polar cap simply results from a projection of the solar wind electric field down open field lines cannot be correct in the general time-dependent case.

Hence the EISCAT-AMPTE data require us to adopt the concept that newly opened flux tubes excite considerable flow in the dayside high-latitude ionosphere, whereas those which have been opened for longer periods are ineffective in driving convection. An estimate of the length of time that a flux tube is effective in driving ionospheric flow following its interconnection with the IMF can be obtained by studying the decay time constant for ionospheric flows following a northward tuming of the IMF. Such results have been presented by Todd et al. [1988a] who found that after a delay of a few minutes (depending on the MLT of the radar observations), the flow speeds decayed rapidly initially (within 2-3 min), followed by a more gradual decline on a time scale of order $10 \mathrm{~min}$. If it is assumed that dayside reconnection ceases immediately when the magnetosheath field turns northward at the magnetopause, it follows from these observations that the ionospheric flow excited by the transfer of dayside flux tubes into the tail declines within about $10 \mathrm{~min}$. We thus conclude that in effect open flux tubes are effective in exciting ionospheric convection for an interval of only $\sim 10 \mathrm{~min}$ following their production at the dayside magnetopause. This time constant is an order of magnitude shorter than the time taken for open flux tubes to traverse the entire polar cap from the dayside cusp to the nightside auroral zone, which is typically between 2 and 4 hours. Indeed, on a time scale of 10 min the newly opened flux tubes traverse a distance of only $\sim 5^{\circ}$ poleward of the dayside cusp, if they move with a typical poleward speed of $-1 \mathrm{~km} \mathrm{~s}^{-1}$. We thus infer that elsewhere within the polar cap the flows occur as an essentially passive response to concurrent dayside conditions (and to concurrent conditions in the near-Earth tail), rather than in response to the dayside conditions which prevailed when these tubes themselves were opened. This inference leads to interesting predictions concerning the rapidity with which polar cap flows respond to sharp changes in the IMF, as will be discussed further in section 5 . In particular, we conclude that flow in the dayside central polar cap will decay to small values (set by any continuing nightside reconnection) on the short (several minute) time scales which were observed at auroral latitudes in the EISCAT-AMPTE data.

At first sight, this conclusion seems to contradict previous observations of polar cap flow. In particular, in a study of transpolar voltage measurements by the $\mathrm{S3-3}$ satellite, Wygant et al. [1983] inferred that following a northward turning of the IMF, residual open flux tubes could continue to drive convection for intervals of up to about 4 hours. However, these cross-cap potential values would include the effects of both residual dayside and continuing nightside reconnection, and the latter can indeed continue to drive ionospheric flow for several hours following a northward turning, particularly on the nightside (compare Figure $1 b$ ). In section 5 we will also retum to this subject and make predictions concerning the time dependence of the observed cross-cap potential for different locations in the polar cap.

\section{3. eiscat Observations of Flows Within the Polar CaP}

The concept of the excitation of ionospheric convection advanced in the previous section was based on EISCAT observations made in the dayside auroral oval. There are a number of predictions implicit in this conceptual model, the most 
important of which is that dayside open field lines can cease moving antisunward on short (few minute) time scales. In this section we present some EISCAT observations of dayside polar cap flow which confirm that this does indeed occur.

Under usual conditions the EISCAT Polar field of view (invariant latitude $\sim 71^{\circ}-75^{\circ}$ ) lies within the polar cap only before dawn and after dusk [Lockwood et al., 1986b, 1988]. Near noon very low flows are usually observed as the field of view is well equatorward of the cusp and lies between the dawn and the dusk cells [Willis et al., 1986; Todd et al., 1988b]. However, on rare occasions the dayside polar cap has been observed within the Polar field of view. On January 12, 1988, the polar cap was sufficiently expanded that the cusp was immediately poleward of the field of view at noon [Lockwood et al., 1989a, b; Sandholt et al., 1990], and the polar cap was entered by mid afternoon. Unfortunately, it is not possible to relate all the variations of the flow which were observed during this interval to the concurrent behavior of the IMF, due to the lack of continuous coverage of data from the IMP-8 spacecraft during the interval studied. Nevertheless, important conclusions can still be drawn from the EISCAT data, and the inferences which are made about the behavior of the IMF during the data gap are supported by some simultaneous flow measurements from the Sondrestromfjord radar.

On this day EISCAT was operating in Common Programme CP-4 mode, an experiment which is identical to Polar except that line-of-sight velocities are recorded every $10 \mathrm{~s}$, rather than 15 s (see van Eyken et al. [1984] and Willis et al. [1986] for a complete description of Polar). The radar beam is pointed at a low elevation $\left(21.5^{\circ}\right)$ to the north of the transmitter site at Troms and is swung between two azimuths $12^{\circ}$ to either side of the local $L$ shell meridian. The radar dwells for 2 min at each azimuth and takes $30 \mathrm{~s}$ to move between them, giving a full cycle time of $5 \mathrm{~min}$. The retum signal from the $F$ region ionosphere is divided into range gates covering the range of invariant latitude $70.8^{\circ}$ to about $75^{\circ}$ (depending on signal strength) in $0.6^{\circ}$ steps. To give field-perpendicular convection vectors, the 12 10-s line-of-sight velocities for each dwell are averaged, and the value of one azimuth is combined with a value for the other azimuth which is linearly interpolated from the values for the preceding and following dwells. This application of the beam-swinging technique gives a vector every 2.5 min for each range gate but introduces some spurious flows and smoothing when large spatial and/or temporal gradients are present (see Lockwood et al. [1988] and Etemadi et al. [1989], respectively). Spurious vectors can be identified by examining the temporal variation of derived flows from one gate and by comparing with results from adjacent gates to check, respectively, for the changes and shears which introduce errors. A further check is to consider the line-of-sight velocities [Todd et al., 1988b; Lockwood and Cowley, 1988]. Note, however, a smoothing effect is always present. As a result of these checks we can confirm that the data described below represent 3-point running means of valid 2.5 -min flow vectors.

The top panel of Figure 2 shows flow data for 0914 UT on January 12, 1988, obtained by the above procedure. As MLT UT +2.75 hours for the field of view, these observations cover the afternoon sector from near noon to just before dusk. In order to reduce congestion of the largely west-east directed flows, each vector has been rotated clockwise by $90^{\circ}$ (such that westward flows, along the $L$ shell, are plotted pointing to the top of the figure, whereas northward flows are to the right). Hence the vectors shown correspond to the ionospheric electric field which is associated with the flow. Also shown in the upper panel of Figure 2 is the approximate location of the poleward edge of $630-\mathrm{nm}$ auroral emissions, as determined from simultaneous observations by a meridian scanning photometer at Ny-Alesund, Spitzbergen (P. E. Sandholt, private communication, 1988). These positions are calculated from the zenith angle above which the $630-\mathrm{nm}$ emission intensity falls to the background level (below $1 \mathrm{kR}$ ) for an assumed emission altitude of $250 \mathrm{~km}$. (See Sandholt [1988] for a review of photometer observations of the cleft/cusp).

The middle panel of Figure 2 shows the potential observed between radar gates 1 and 7 [the nearest and furthest gates shown in Figure $2 a), \Phi_{17}$. This value is obtained by integrating the observed northward electric field across the north-south dimension of the radar field of view. Positive $\Phi_{17}$ indicates that the potential in gate 1 exceeds that in gate 7 such that the flow between them is predominantly westward. The bottom three panels of Figure 2 show the magnitude $\left(B_{T}\right)$, azimuth $(\phi)$ and elevation $(\theta)$ of the IMF, in GSE coordinates, observed simultaneously by the IMF-8 spacecraft (R. P. Lepping, private communication, 1988). At this time, IMP-8 was located near the dawn meridian at GSE coordinates $X=-4.5 R_{E}, Y=$ $-33.0 R_{E}$ and $Z=8.0 R_{E}$.

It can be seen that prior to about $1120 \mathrm{UT}$, the flows are consistently westward within the radar field of view but variable in magnitude. We thus infer that during this interval the radar is predominantly observing the auroral zone flow in the dusk convection cell. However, it should be noted that the auroral cusp/cleft emissions lie just poleward of the radar field of view, which may therefore at times also contain open field lines. The IMF $B_{Y}$ component was continuously positive during this period as can be seen from the azimuth of the IMF vector ( $B_{Y} \approx 10 \mathrm{nT}$ in GSM coordinates), so that westward flows are expected to be present on newly reconnected northern hemisphere open cusp field lines, due to the tension of the magnetic field [Jorgensen et al., 1972; Cowley, 1981; Saunders, 1989]. The detailed relationship of the flow bursts (seen most clearly in the peaks in $\Phi_{17}$ ), to transient dayside aurorae and the IMF during this period has been discussed recently by Lockwood et al. [1989a, b] and Sandholt et al. [1990], and will not be repeated here, other than to note that the combined data sets provide very strong evidence that these bursts represent the ionospheric signatures of flux transfer events at the magnetopause. Figure $3 a$ provides a simple sketch of the inferred convection pattern at this time. The thin solid lines show flow streamlines and the heavy lines the open/closed field line boundary, the dashed part of which is the ionospheric projection of the magnetopause neutral line (i.e., the merging gap). The pair of short lines drawn from the point marked $T$ (for Troms $\varnothing$ ) represent the two beam directions of the Polar experiment, and the shaded region gives the latitude range covered by gates 1 to 7

The major concern of this section is the sequence of events after $1120 \mathrm{UT}$, which commences with a rotation of the vectors derived for gate 7 from westward to eastward via northward. It should be noted that the beamswinging technique will tend to give rise to such a rotation of the derived vectors, even if the reversal which moves over the field of view is, in reality, a shear. Lockwood et al. [1988] have modeled this effect and have shown that an apparent slowing of the flow and a spurious northward flow at the boundary will be caused by a moving shear reversal. The data shown in Figure $2 a$ are consistent with such a shear (adiaroic) reversal moving equatorward over gate 


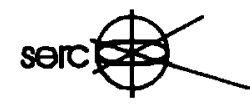

EISCAT CP-4-A 12 January 1988

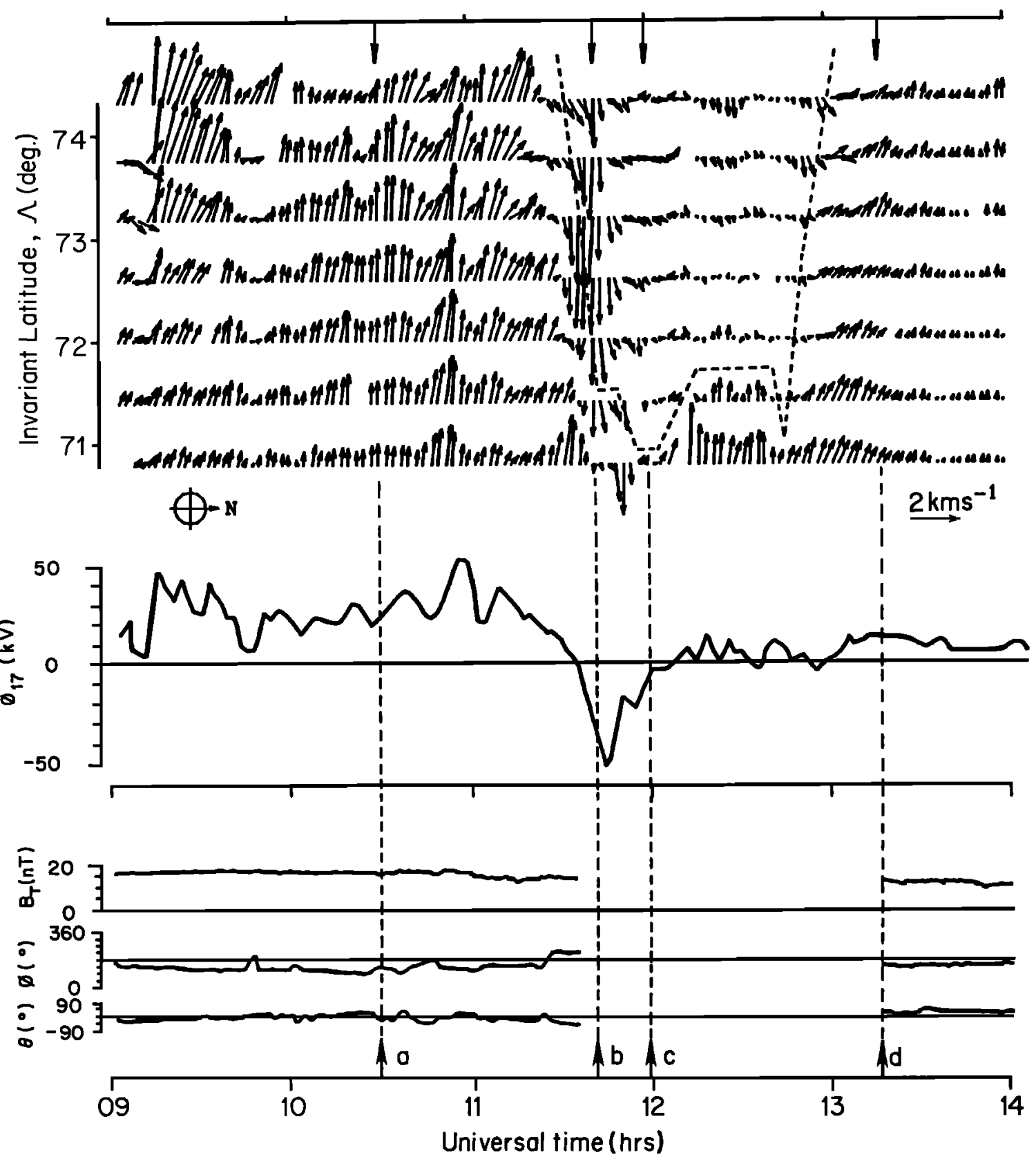

Fig. 2. Data from the EISCAT Common Programme CP-4 (Polar) experiment on January 12, 1988. The top panel shows flow vectors, which have been rotated clockwise by $90^{\circ}$ to avoid congestion, such that northward flow points to the right and westward flow up the page (i.e., the vectors have been drawn in the direction of the convection electric field). Vectors are shown for gates 1 to 7 as a function of invariant latitude and UT (MLT - UT + 2.75 hours). The dashed line gives the location of the poleward edge of the 630-nm cleft aurora (intensity $1 \mathrm{kR}$ ), as observed from Ny Alesund, Spitzbergen, for an assumed emission altitude of $250 \mathrm{~km}$. The middle panel shows the electric potential between radar gates 1 and 7, $\Phi_{17}$, obtained by integrating the north-south electric field, associated with the cast-west flow, across the field of view. A positive value indicates predominantly westward flow. The three bottom panels give the magnitude $(B T)$, and azimuth $(\phi)$ and elevation $(\theta)$ angles (GSE), respectively, of the IMF vector observed simultaneously by the IMP-8 spacecraft located at GSE $(X, Y, Z)=(-4.5,-33.0,8.0) R_{E}$. The times marked a-d refer to the flow schematics shown in Figure 3 .

7 at about 1125 UT. Similar reversals were subsequently observed at nearer range gates as the boundary moved across the entire field of view in 15 min, giving eastward flow at all range gates by about 1140 UT. This motion of the boundary, and the direction of the flow observed within the polar cap, is consistent with a change in the IMF $B_{\boldsymbol{Y}}$ component which was observed by IMP-8 at 1126 UT (see Lockwood et al. [1989b] for calculations of the satellite-to-radar propagation delays on 


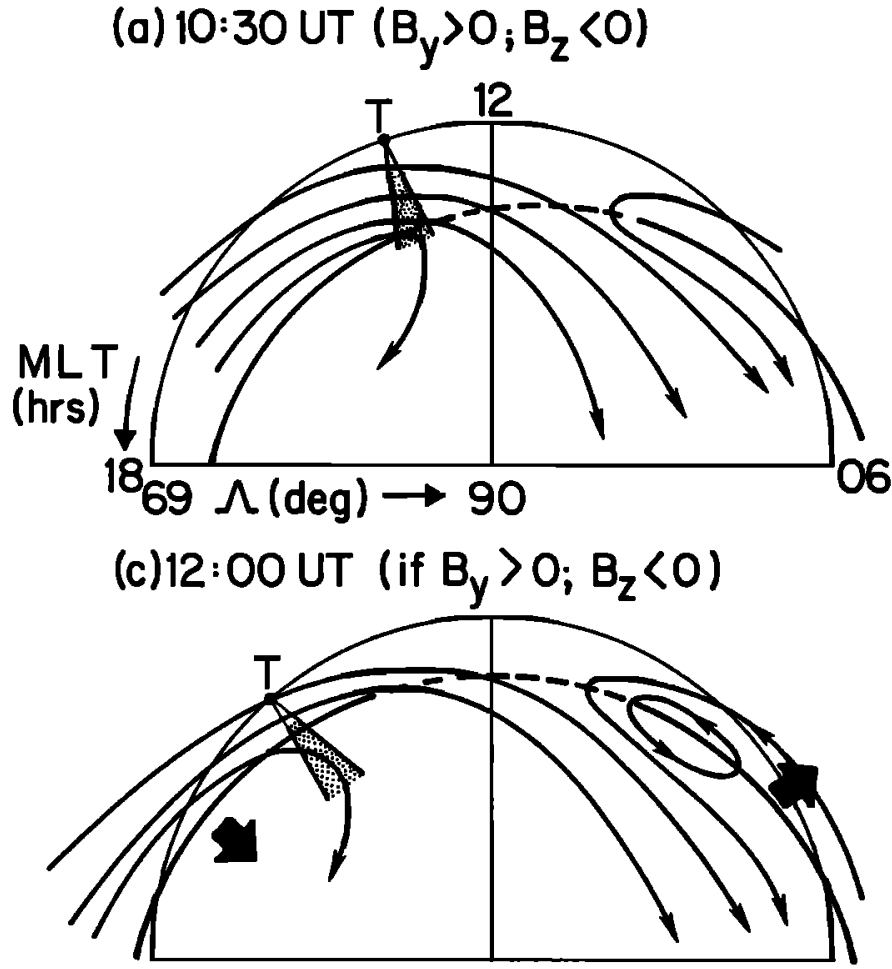

$$
\text { (b) 11:40UT }\left(B_{y}<0, B_{z}<0\right)
$$
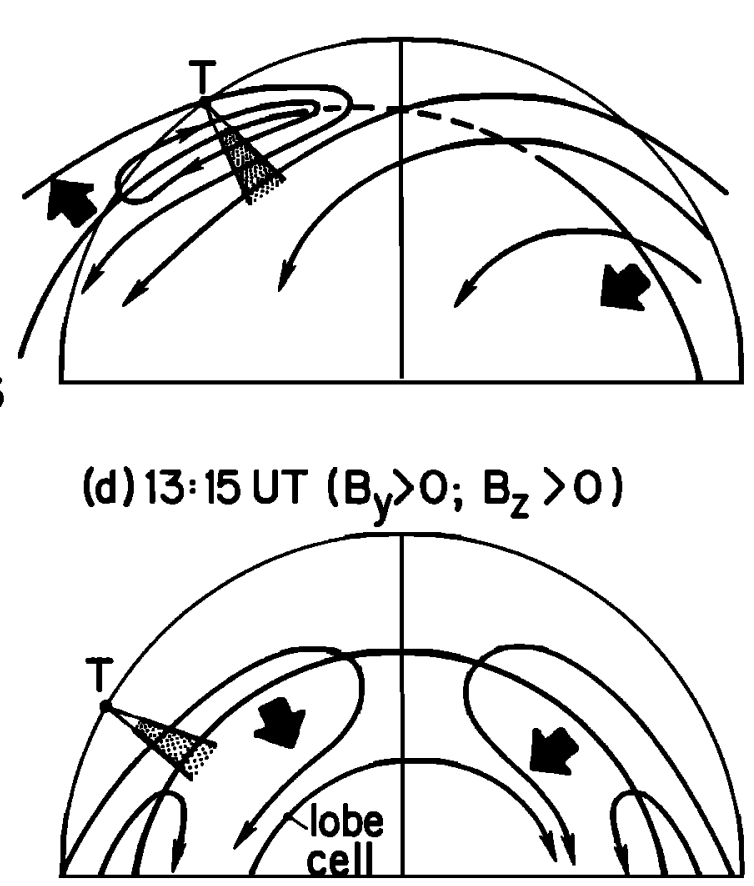

Fig. 3. Sequence of flow schematics illustrating the interpretation of the data presented in Figure 2. Flow streamlines, and the polar cap boundary and its motion, are depicted as in Figure 1. The point $T$ shows the position of the EISCAT transmitter site at Troms relative to the flow pattem, with the two short straight lines indicating the two Polar beam pointing directions. The thaded area represents the radar field of view between gates 1 and 7.

this day). For $B_{\Upsilon}<0$ the magnetic tension effect on open flux tubes produces eastward flow in the northern hemisphere cusp, and spacecraft observations have shown that the polar cap boundary is displaced toward dusk under these conditions [Cowley, 1981; Cowley and Hughes, 1983]. Hence we interpret the flows seen after the change in IMF $B_{Y}$ with Figure $3 b$, where the eastward flows in all range gates at $1140 \mathrm{UT}$ are depicted as being wholly on open field lines. In principle, a viscous-like interaction could allow at least some of this flow to be located on closed field lines. However, it should be noted that the voltage across the radar field of view is $\Phi_{17}=-55 \mathrm{kV}$ at this time. We are not aware of any observations which suggest that viscous-like mechanisms can generate a voltage this large across closed boundary layers. Measured values indicate that the total viscously-driven voltages are no more than 1-10 kV [Mozer, 1984], consistent with ground-based observations indicating potential differences of $3.5 \mathrm{kV}$ over 1 hour MLT segments of the polar cap boundary [Lockwood et $a l ., 1988$ ]. Furthermore, the dashed line shows that by this time gates 2-7 are poleward of any 630-nm emissions. The absence of any such emission is only expected on open flux tubes well within the polar cap. This is because plasma injected from the magnetosheath onto open field lines will subsequently precipitate poleward of the open/closed field line boundary, because of the velocity filter effect due to antisunward convection [Heikkila and Winningham, 1971; Rosenbauer et al., 1975; Reiff et al., 1977]. Hence the location of the 630-nm aurora strongly supports the inference that the radar field of view $w$ as well within the polar cap by 1140 UT.

Shortly after the eastward flow is established in all range gates, a rapid slowing of the flow was observed, which occurred approximately simultaneously in all range gates. From peak eastward flow speeds of $2-3 \mathrm{~km} \mathrm{~s}^{-1}$, the flow decayed to a few hundred $\mathrm{m} \mathrm{s}^{-1}$ northward in only 5-10 min. During this decline the flux tubes in the poleward part of the radar field of view (inferred from the above discussion to be open) generally moved east by a distance which is less than the distance between the two radar beams. For example, for gate 7 the two scattering volumes are $410 \mathrm{~km}$ apart, whereas the flux tubes moved only $300 \mathrm{~km}$ eastward during the decline in flow. In effect, therefore, individual flux tubes slowed from 2 to $3 \mathrm{~km}$ $\mathrm{s}^{-1}$, almost to rest in about 5-10 min, whilst mainly remaining within the radar field of view. Hence these observations show in a direct way that the flow of open field lines in the ionosphere can decay from large values to essentially nothing within 5-10 min. This time scale is, of course, close to the resolution limit of the vector radar data. However, examination of the 10-s line-of-sight velocities (not shown here) gives a similar time scale for the decay as for the vectors shown in Figure 2.

Because of the gap in the IMF data, we cannot be certain of the cause of this change in the flow. By the time IMF data become available again (1315 UT) both IMF $B_{Y}$ and $B_{Z}$ had changed sense (see IMF $\phi$ and $\theta$ angles in Figure 2). From the EISCAT data we infer that the flow change was in fact due to a change in IMF $B_{Y}$, because westward flow persisted in range gate 1 after the slowing of the flow in the polar cap, thus suggesting the flow pattern shown in Figure 3c. The cap boundary at the MLT of the observations is shown as adiaroic because the northward flow observed in gates 4 to 7 was roughly $300 \mathrm{~m} \mathrm{~s}^{-1}$ which is close to the velocity of $200 \mathrm{~m} \mathrm{~s}^{-1}$ with which the boundary returned poleward over gates 1 and 2 . The interpretation given by Figure $3 c$ is supported by simultaneous data taken by the Sondrestrom radar (O. de la Beaujardiere and C. R. Clauer, private communications, 1988). These 
observations commence at 1213 UT (i.e., 20 min after the decay of polar cap flow observed by EISCAT) and show flows near 0930 MLT which are consistent with Figure $3 c$, with the sunward apex of the dawn cell lying equatorward of strong (2-3 $\mathrm{km} \mathrm{s} \mathrm{s}^{-1}$ ) north westward flow.

This flow pattem was then maintained until roughly 1250 UT, when we infer that a northward tuming of the IMF reached the magnetopause. Subsequently, the polar cap boundary moved smoothly poleward, and by 1315 UT (when the IMF is known to be northward), weaker ( $<1 \mathrm{~km} \mathrm{~s}^{-1}$ ) westward (auroral zone) flow was established in all range gates. During this period, Sondrestrom observed a series of flow decays and enhancements as it scanned through invariant latitudes below $78^{\circ}$, but by 1315 UT the flow had all but disappeared. At latitudes above $78^{\circ}$ the flow speeds were maintained but rotated from north-westward to westward during this period. We conclude that Sondrestromfjord, like EISCAT, observed the decay of the convection flow cells driven by dayside reconnection at the subsolar magnetopause (as shown schematically in Figure 3d), but also observed the establishment of a "lobe" cell at the highest latitudes (also shown in Figure 3d), due to the onset of reconnection at the northern tail lobe magnetopause following the northward turning of the IMF; the westward flows are consistent with the positive IMF $B_{Y}$ observed.

\section{Discussion and Conclusions}

The principal aim of this paper is to point out that a change is required in the paradigm used to interpret observations of high-latitude ionospheric convection. In recent years, the recognition of the dominant role played by the orientation and strength of the IMF has generally led to the analysis of flow and voltage data in terms of flow configurations ordered by the IMF [e.g. Reiff et al., 1981; Doyle and Burke, 1983; Wygant et al., 1983; Heelis, 1984; Friis-Christensen et al., 1985; Heppner and Maynard, 1987; Holt et al., 1987]. For steady state flows (and in the absence of significant field-aligned voltages over large areas), the electric field in the ionospheric polar cap may then be viewed as the direct image of the magnetosheath electric field, mapped down the open field lines. However, following the theoretical concepts advanced by Siscoe and Huang [1985], and the results of analyses of geomagnetic disturbance data and recent radar data (reviewed here in section 2), we propose that the flow must instead be viewed as a combination of two intrinsically time-dependent flow patterns which are, to a large extent, decoupled from one another.

One of these two flow patterns is "directly" driven by coupling between the solar wind and the magnetosphere taking place at the dayside magnetopause. From the response of the flows to changes in the IMF, we infer that this coupling is largely due to magnetic reconnection, although other mechanisms may contribute. These flows dominate in the dayside high-latitude ionosphere and will generally be associated with an expanding polar cap area. The second flow pattem is associated with flux return from the geomagnetic tail, principally (but not necessarily exclusively) due to magnetic reconnection during substorms. These flows dominate in the nightside ionosphere and will generally be associated with a contracting polar cap area. Broadly speaking, the first of these two patterns is the flow equivalent of the DP-2 current system and dominates during the growth phase of substorms. The second is associated with the DP-1 current system (the electrojet-associated "current wedge") and dominates during the substorm expansion phase. Because this second system is largely driven by the explosive release of energy and magnetic stress stored in the geomagnetic tail, it will be largely decoupled from the directly-driven flows which dominate the dayside high-latitude ionosphere. Hence the singular case of equal dayside and nightside reconnection rates (i.e., steady state convection) will rarely, if ever, be achieved, so that only rarely can the ionospheric electric field be regarded as a direct map of that in the magnetosheath.

A necessary corollary of this paradigm of ionospheric convection is that the field-aligned current systems associated with high-latitude convection will also consist of two, essentially decoupled, components, one dominant on the dayside, the other on the nightside. Recent analysis of data from ground-based magnetometers [Friis-Christensen and Lassen, 1990] suggests that the region 1 currents are indeed split into two such distinct parts (regions "1A" and "1B"). Similar conclusionis have been reached from analysis of satellite magnetic field data using a model magnetospheric field configuration [Spence et al., 1988].

The decoupled nature of the two flow systems is principally made manifest in ground-based data in the different time scales with which they respond to changes in the IMF. High-resolution studies of the dayside flow system using the EISCAT Polar and $\mathrm{CP}-4$ experiments have shown that these flows respond rapidly to changes in the IMF, in both their excitation and decay. For example, following a southward turning of the magnetic field at the subsolar magnetopause, a new flow pattern is excited near noon within a few minutes and has been observed to expand, establishing large-scale flow of the type shown in Figure $1 a$ within 10-15 $\mathrm{min}$.

The magnitude and detailed form of these flows are determined by the IMF $B_{Z}$ and $B_{Y}$ components. Similarly, following a northward tuming of the IMF, this flow pattern is found to decay on a time scale of about $10 \mathrm{~min}$. Bearing in mind that some open flux is always present in the polar cap and that a typical transit time of an open flux tube across the polar cap is 2-4 hours, we must conclude that only newly opened flux tubes are effective in generating flow in the ionosphere. The data indicate that the production of newly opened flux tibes at the dayside magnetopause generates flow only for a period of about $10 \mathrm{~min}$. During this interval the open tubes typically move only $-600 \mathrm{~km}$ in the ionosphere, i.e. to an invariant latitude about $5^{\circ}$ poleward of the merging gap. Also during this interval the point where the same flux tube threads the magnetopause will move a total distance of only $-30 R_{E}$ from the reconnection line at the nose of the magnetosphere, to an $X$ coordinate of about $-10 R_{E}$. This distance compares with a total tail length of typically $\sim 500$ to $1000 R_{E}$. Clearly, such transfers of magnetic flux from the dayside magnetosphere into the tail will disturb the equilibrium of the near-Earth field and plasma configuration and will excite large-scale flows in this region as observed, as the system adjusts to the new flux configuration. However, the inference appears to be that once an open tube has been carried into the near-Earth tail lobe, its further stretching downstream by the magnetosheath flow produces little additional change in the nearEarth configuration, and thus, of itself, little further near-Earth flow. The subsequent motion of these open tubes in the near-Earth regime will then mainly be in response to subsequent flux transfers to and from the tail due, for example, to dayside and nightside reconnection, respectively, rather than being due in any direct way to the fact that the magnetosheath "ends" of these tubes are being carried continu- 
ously in the antisolar direction by the magnetosheath flow. In particular, if no further flux transfers to or from the tail occur, then convective flows will cease in the near-Earth magnetosphere and ionosphere, even though open flux continues to be present. In this situation a large electric field will of course be present transverse to the open field lines in the magnetosheath and solar wind, yet the electric field in the ionosphere on the same field lines will be essentially zero. The implication is just that the electric field has a curl such that the tail magnetic field configuration is changing with time. This change corresponds simply to the continuous antisolar stretching of the open flux tubes by the solar wind flow.

Because it is associated with the storage and release of energy in the geomagnetic tail, the nightside flow and current system should be less directly controlled by the IMF. From studies of isolated substorms, however, it has been found that there is a characteristic response delay of $\sim 30-60 \mathrm{~min}$ after a southward tuming of the IMF, compared with the 1-2 min for the dayside response near noon. Rapid reconnection in the tail which occurs in the expansion phase of a substorm thus typically begins after a growth phase lasting several tens of minutes during which only the dayside flow pattern is enhanced, the polar cap expands and there is a net transfer of flux into the tail. During the expansion phase the nightside flow pattern is enhanced and the polar cap contracts. To date, most studies of the response of the nightside system have employed geomagnetic disturbance data. It is therefore highly desirable that in future the high-time resolution radar flow measurements be extended to also cover the nightside, as has recently been initiated by Williams et al. [1989].

The present state of knowledge, however, is sufficient to show that a sequence of flow patterns ordered by the strength and orientation of the IMF, is an inherently inadequate description of high-latitude convection. Rather, the flow should be viewed as the superposition of two inherently time-dependent pattems, one of which dominates the dayside high-latitude ionosphere and responds to the IMF on time scales of about 10 min while the other is dominant in the nightside high-latitude ionosphere, is less directly related to the IMF and has response lags of about an hour. (Note, however, that the "nightside" pattern still has some influence on dayside flows and viceversa). The former pattem is associated with expansion of the polar cap, and the latter with its contraction. In the general case, both flow systems will be present, and the variation of the polar cap area with time will be determined by the difference between the voltages across the dayside and nightside merging gaps in their respective rest frames, in accordance with Faraday's Law. The voltages along the merging gaps (in the Earth's frame) also determine the relative strengths of the dayside and nightside flow patterns. With this view of convection, it is clear that no unique flow pattern can be associated with any given IMF vector, since even if the dayside flow pattem can be taken to adjust rapidly to the prevailing IMF conditions, the overall flow will still depend on the history of the IMF for two reasons. First, the nightside flows have a much longer response time to IMF changes, and second, the flow locations will depend upon the absolute size (and shape) of the polar cap. The first of these two effects may account for at least some of the scatter in the cross-cap voltage measurements obtained for a given IMF $B_{Z}$ (see the reviews by Cowley [1982, 1984, 1986], and Reiff and Luhmann [1986]). In the study by Wygant et al. [1983], the residual cross-cap voltage showed considerable scatter at a given time following a northward tuming of the IMF. This scatter is readily explained by the variety of satellite orbits included in their study (covering roughly $20^{\circ}$ about the center of the polar cap in the $X$ direction); the decay time will be longer for passes across the nightside polar cap, where the nightside system may be maintained by release of energy stored in the geomagnetic tail.

\section{Predictions}

In the previous sections we have shown how the proposed concept of high-latitude convection readily accounts for the observed properties of high-latitude flows and current systems and their response to changes in interplanetary conditions. However, a number of predictions are also suggested by this picture, as enumerated below:

1. The region 1 currents should show two distinct parts, with peaks near the ends of the dayside and nightside merging gaps. These two systems should show very different response times to changes in IMF $B_{Z}$.

2. The decay time of the cross-cap voltage following a northward turning of the IMF, as estimated from low-altitude spacecraft data, will vary from a few minutes for passes just poleward of the dayside merging gap to an hour or more for passes just poleward of the nightside merging gap, due to continuing flows associated with nightside reconnection.

3. Bursts of dayside reconnection in "flux transfer events" will only be visible in the ionosphere while they are generating flows which are enhanced relative to the background flow [Southwood, 1987, 1989]. Our results indicate that this situation will persist for at most $\sim 10 \mathrm{~min}$ and hence that such transients will be short-lived and confined to a narrow region just poleward of the cleft. Their displacement in the ionosphere during this interval will thus generally be by an amount which is not much greater than their own spatial extent.

4. The last prediction concerns the rapidity of the response of flows in the central polar cap to changes in IMF $B_{Y}$. The response to IMF $B_{Z}$ near the pole will be complex as the nightside and dayside patterns will have roughly equal influence. However, it is well known that the flow in the central polar cap exhibits dawn-dusk asymmetries which depend upon the magnitude and sense of the IMF $B_{Y}$ component. On the basis of the concepts presented here we predict that this asymmetry should respond directly and rapidly (within 10-15 min) to changes in the $B_{Y}$ component. Hence, following a change in sense of IMF $B_{Y}$, the polar cap flow will exhibit the asymmetry associated with the new sense of $B_{Y}$ within this period, even though most of the polar cap flux tubes remain connected to an IMF of the opposite polarity (because they were connected before the IMF $B_{Y}$ change).

Acknowledgments. The authors are grateful to D. J. Southwood, R. A. Heelis, P. H. Reiff and M. A. Saunders for useful discussions, to K. S. Freeman for processing the EISCAT CP-4 data and to the director and staff of EISCAT and $\mathrm{K}$. J. Winser for their efforts in obtaining the EISCAT radar data. We also thank $O$. de la Beaujardiere and $C$. $R$. Clauer for providing data from the Sondrestrom radar, P. E. Sandholt for the provision of photometer data, and R. P. Lepping for the IMP- 8 magnetometer data. EISCAT is supported by research councils of France (CNRS), Federal Republic of Germany (MPG), Sweden (NAVF), Norway (NF) and the UK (SERC).

The Editor thanks R. A. Heelis and another referee for their assistance in evaluating this paper.

\section{REFERENCES}

Amoldy, R. L., Signature in the interplanetary medium for substorms, $J$. Geophys. Res., 76, 5189, 1971. 
Baker, D. N., E. W. Hones, Jr., J. B. Payne, and W. C. Feldman, A high time resolution study of interplanetary parameter correlations with $A_{E}$, Geophys. Res. Lett., 8, 179, 1981.

Baker, D. N., R. D. Zwickl, S. J. Bame, E. W. Hones, Jr., B. T. Tsurutani, E. J. Smith, and S. I. Akasofu, An ISEE-3 high time resolution study of the interplanetary parameter correlations with magnetospheric activity, J. Geophys. Res., 88, 6230, 1983.

Bargatze, L. F., D. N. Baker, R. L. McPherron, and E. W. Hones, Jr., Magnetospheric impulse response for many levels of geomagnetic activity, J. Geophys. Res., 90, 6387, 1985.

Berchem, J., and C. T. Russell, Flux transfer events on the magnetopause: Spatial distribution and controlling factors, J. Geophys. Res., 89, 6689, 1984.

Burke, W. J., M. C. Kelley, R. C. Sagalyn, M. Smiddy, and S. T. Lai, Polar cap electric field structures with a northward interplanetary magnetic field, Geophys. Res. Lett., 6, 21, 1979.

Claver, C. R., and E. Friis-Christensen, High-latitude dayside electric fields and currents during strong northward interplanetary magnetic field: Observations and model simulation,J. Geophys. Res., 93, 2749, 1988.

Clauer, C. R., and Y. Kamide, DP1 and DP2 current systems for March 22, 1979, substorms, J. Geophys. Res., 90, 1343, 1985.

Clauer, C. R., R. L. McPherron, C. Searles, and M. G. Kivelson, Solar wind control of auroral zone magnetic activity, Geophys. Res. Lett., $8,915,1981$.

Coley, W. R., R. A. Heelis, W. B. Hansen, P. H. Reiff, J. R. Sharber, and J. D. Winningham, Ionospheric convection signatures and magnetic field topology, J. Geophys. Res., 92, 12352, 1987.

Cowley, S. W. H., Magnetospheric asymmetries associated with the Y-component of the IMF, Planet. Space Sci., 29, 79, 1981.

Cowley, S. W. H., The causes of convection in the Earth's magnetosphere, A review of developments during the IMS, Rev. Geophys., 20 , 531, 1982.

Cowley, S. W. H., Solar wind control of magnetospheric convection, in Achievements of the International Magnetospheric Study, IMS, p. 483, Noordwijk, Netherlands, 1984.

Cowley, S. W. H., The impact of recent observations on theoretical understanding of solar wind-magnetosphere interactions, J. Geomagn. Geoelectr., 38, 1223, 1986.

Cowley, S. W. H. and W. J. Hughes, Observation of an IMF sector effect in the $\boldsymbol{Y}$ magnetic field component at geostationary orbit, Planet. Space Sci., 31, 73, 1983.

de la Beaujardiere, O., D. S. Evans, Y. Kamide, and R. P. Lepping, Response of the auroral oval precipitation and magnetospheric convection to changes in the interplanetary magnetic field, Ann. Geo. phys., SA, 519, 1987.

Doyle, M. A., and W. J. Burke, S3-2 measurements of polar cap potential, J. Geophys. Res., 88, 9125, 1983.

Dungey, J. W., The structure of the exosphere or adventures in velocity space, in Geophysics, the Earth's Environment, edited by C. DeWitt, J. Hieblot, and A. Lebeau, p. 503, Gordon and Breach, New York, p. $503,1963$.

Etemadi, A., S. W. H. Cowley, M. Lockwood, B. J. I. Bromage, D. M. Willis, and $\mathrm{H}$. Luhr, The dependence of high-latitude dayside ionospheric flows on the north-south component of the IMF, a high time resolution correlation analysis using EISCAT "POLAR" and AMPTE UKS and IRM data, Planet. Space Sci., 36, 471, 1988.

Etemadi, A., S. W. H. Cowley, and M. Lockwood, The effect of rapid changes in ionospheric flow on velocity vectors deduced from radar beamswinging experiments, J. Atmos. Terr. Phys., 51, 125, 1989.

Freeman, M. P., and D. J. Southwood, The effects of magnetospheric erosion on mid and high latitude ionospheric flows, Plenet. Space Sci., 36, 509, 1988.

Freeman, M. P., C. J. Farrugia, S. W. H. Cowley, and A. Etemadi, The response of dayside ionospheric convection to the $Y$-component of magnetosheath magnetic field, Planet. Space Sci., 38, 13, 1990.

Friis-Christensen, E., and K. Lassen, Large-scale distribution of discrete auroras and field-aligned currents, in Auroral Physics, edited by C.-I. Meng, M. J. Rycroft, and L. A. Frank, p. 339, Cambridge University Press, 1990.

Friis-Christensen, E., Y. Kamide, A. D. Richmond, and S. Matsushita, Interplanetary magnetic field control of high-latitude electric fields and currents determined from Greenland magnetometer data, J. Geophys. Res., 90, 1325, 1985.

Heelis, R. A., The effects of interplanetary magnetic field orientation on dayside high-latitude convection, J. Geophys. Res., 89, 2873, 1984.

Heelis, R. A., J. C. Foster, O. de Ia Beaujardiere, and J. M. Holt,
Multistation measurement of high-latitude ionospheric convection, J. Geophys. Res., 88, $10111,1983$.

Heikkila, W. J., and J. D. Winningham, Penetration of magnetosheath plasma to low altitudes through the dayside magnetospheric cusps, $J$. Geophys. Res., 76, 883, 1971.

Heppner, J. P., and N. C. Maynard, Empirical high-latitude electric field models, J. Geophys. Res., 92, 4467, 1987.

Holt, J. M., R. H. Ward, J. V. Evans, and W. L. Oliver, Empirical models for the plasma convection at high latitudes from Millstone Hill observations, J. Geophys. Res., 92, 203, 1987.

Holzer, T. E., R. L. McPherron, and D. A. Hardy, A quantitative empirical model of the magnetospheric flux transfer process, J. Geophys. Res., 91, 3287, 1986.

Hones, E. W., Jr., Transient phenomena in the magnetotail and their relation to substorms, Space Sci. Rev., 23, 393, 1979.

Jorgensen, T. S., E. Friis-Christensen, and J. Wilhjelm, Interplanetary magnetic field direction and high-latitude currents, J. Geophys. Res., 77, 1976, 1972.

Lockwood, M., and S. W. H. Cowley, Observations at the magnetopause and in the auroral ionosphere of momentum transfer from the solar wind, Adv. Space Res., 8, 281, 1988.

Lockwood, M., and M. P. Freeman, Recent ionospheric observations relating to solar wind-magnetosphere coupling, Philos. Trans. R. Soc. London, Ser. A, 328, 93, 1989.

Lockwood, M., A. P. van Eyken, B. J. I. Bromage, D. M. Willis, and S. W. H. Cowley, Eastward propagation of a plasma convection enhancement following a southward turning of the interplanetary magnetic field, Geophys. Res. Lett., 13, 72, 1986a.

Lockwood, M., A. P. van Eyken, B. J. I. Bromage, J. H. Waite, Jr., T. E. Moore, and J.R. Doupnik, Low-energy ion outflows from the ionosphere during a major polar cap expansion-evidence for equatorward motion of inverted-V events, Adv. Space Res., 6(3), 93, $1986 b$.

Lockwood, M., S. W. H. Cowley, H. Todd, D. M. Willis, and C. R. Clauer, Ion flows and heating at a contracting polar cap boundary, Planet. Space Sci., 36, 1229, 1988.

Lockwood, M., P. E. Sandholt, and S. W. H. Cowley, Dayside auroral activity and momentum transfer from the solar wind, Geophys. Res. Lett., 16, 125, 1989a.

Lockwood, M., P. E. Sandholt, S. W. H. Cowley, and T. Oguti, Interplanetary magnetic field control of dayside auroral activity and the transfer of momentum across the dayside magnetopause, Planet. Space Sci., 37, 1347, 1989 b.

Lyons, L. R., A simple model for polar cap convection pattems and generation of auroras, J. Geophys. Res., 90, 1561, 1985.

McPherron, R. L., and R. H. Manka, Dynamics of the 1054 UT March 2. 1979, substorm event: CDAW 6, J. Geophys. Res., 90, 1175, 1985.

Mitchell, D. G., F. Kutchko, D. J. Williams, T. E. Eastman, L. A. Frank, and C.T. Russell, An extended study of the low-latitude boundary layer on the dawn and dusk flanks of the magnetosphere, J. Geophys. Res., 92, 7394, 1987.

Moses, J. J., G. L. Siscoe, N, U. Crooker, and D. J. Gomey, IMF By and day-night conductivity effects in the expanding polar cap convection model, J. Geophys. Res., 92, 1193, 1987.

Moses, J. J., G. L. Siscoe, R. A. Heelis, and J. D. Winningham, Polar cap deflation during magnetospheric substorms, J. Geophys. Res., 94, $3785,1989$.

Mozer, F. S., Electric field evidence for viscous interaction at the magnetopause, Geophys. Res. Letl., 11, 981, 1984.

Nishida, A., Coherence of geomagnetic DP 2 fluctuations with interplanetary magnetic variations, J. Geophys. Res., 73, 5549, 19680.

Nishida, A., Geomagnetic DP 2 fluctuations and associated magnetospheric phenomena, J. Geophys. Res., 73, 1795, 1968 b.

Nishida, A., and Y. Kamide, Magnetospheric processes preceding the onset of an isolated substorm: A case study of the March 31, 1978 substorm, J. Geophys. Res., 88, 7005, 1983.

Paschmann, G., I. Papamastorakis, W. Baumjohann, N. Sckopke, C. W. Carlson, B. U. O. Sonnerup, and H. Luhr, The magnetopause for large magnetic shear, J. Geophys. Res., 91, $11099,1986$.

Pellinen, R. J., W. Baumjohann, W. J. Heikkila, V. A. Sergeev, A. G. Yahnin, G. Marklund, and A. O. Melnikov, Event study on pre-substorm phases and their relation to the energy coupling between the solar wind and magnetosphere, Planet. Space Sci., 30, 371, 1982.

Reiff, P. H., Sunward convection in both polar caps, J. Geophys. Res., $87,5976,1982$.

Reiff, P. H., and J. L. Burch, IMF $B_{y}$-dependent plasma flow and Birkeland currents in the dayside magnetosphere, 2, A global model for northward and southward IMF, J. Geophys. Res., 90, 1595, 1985. 
Reiff, P. H., and J. G. Luhmann, Solar wind control of the polar cap voltage, in Solar Wind-Magnelosphere Coupling, edited by $\mathbf{Y}$. Kamide and J. A. Slavin, p. 453, Terra Scientifica, Tokyo, 1986.

Reiff, P. H., T. W. Hill, and J. L. Burch, Solar wind plasma injection in the dayside magnetospheric cusp, J. Geophys. Res., 82, 479, 1977.

Reiff, P. H., R. W. Spiro, and T. W. Hill, Dependence of polar cap potential drop on interplanetary parameters, $J$. Geophys. Res., 86, 7639, 1981.

Reiff, P. H., R. W. Spiro, R. A. Wolf, Y. Kamide, and J. H. King, Comparison of polar cap potential drops estimated from solar wind and ground magnetometer data: CDAW 6, J. Geophys. Res., 90, 1318, 1985.

Richardson, I. G., C. J. Owen, S. W. H. Cowley, A. B. Galvin, T. R. Sanderson, M. Scholer, J. A. Slavin, and R. D. Zwickl, ISEE-3 observations during the CDAW-8 intervals: case studies of the distant geomagnetic tail covering a wide range of geomagnetic activity, $J$. Geophys. Res., 94, $15189,1989$.

Richmond, A. D., Y. Kamide, B.-H. Ahn, S.-I. Akasofu, D. Alcayde, M. Blanc, O. de la Beaujardiere, D. S. Evans, J. C. Foster, E. Friis-Christensen, T. J. Fuller-Rowell, J. M. Holt, D. Knipp, H. W. Kroehl, R. P. Lepping, R. J. Pellinen, C. Senior, and A. N. Zaitzev, Mapping electrodynamic features of the high-latitude ionosphere from localized observations: Combined incoherent scatter radar and magnetometer measurements for January 18-19, 1984, J. Geophys. Res., 93, $5760,1988$.

Rijnbeek, R. P., S. W. H. Cowley, D. J. Southwood, and C. T. Russell, A survey of dayside flux transfer events observed by the ISEE-1 and -2 magnetometers, J. Geophys. Res., 89, 786, 1984.

Rishbeth, H., P. R. Smith, S. W. H. Cowley, D. M. Willis, A. P. van Eyken, B. J. I. Bromage, and S. R. Crothers, Ionospheric response to changes in the interplanetary magnetic field observed by EISCAT and AMPTE-UKS, Nature, 318, 451, 1985.

Rosenbauer, H., J. Grunwaldt, M. D. Montgomery, G. Paschmann, and N. Sckopke, HEOS-2 plasma observations in the distant polar magnetosphere: The plasma mantle, J. Geophys. Res., 80, 2723, 1975.

Russell, C. T. The configuration of the magnetosphere, in Critical Problems of Magnetospheric Physics, edited by E. R. Dyer, p. 1. National Academy of Sciences, Washington, D. C., 1972.

Russell, C. T., and R. L. McPherron, The magnetotail and substorms, Space Sci. Rev., 15, $205,1973$.

Rycroft, M. J., The electrodynamics and magnetohydrodynamics of geospace, Mem. Nall. Inst. Polar Res., 48, 196, 1987.

Sandholt, P. E., IMF control of the polar cusp aurora, Adv. Space Res., $8(9), 21,1988$.

Sandholt, P. E., M. Lockwood, T. Oguti, S. W. H. Cowley, K. S. C. Freeman, A. Egelend, B. Lybekk, and D. M. Willis, Momentum transfer from the magnetosheath to the ionosphere in relation to dayside aurora, J. Geophys. Res., 95, 1039, 1990.

Saunders, M. A., Origin of the cusp Birkeland currents, Geophys. Res. Lett., 16, 151, 1989.

Schatten, K. H., and J. W. Wilcox, Response of geomagnetic activity index $\boldsymbol{K}_{p}$ to interplanetary magnetic field, J. Geophys. Res., 72, 5185 , 1967.

Schunk, R. W., Magnetosphere-ionosphere-thermosphere coupling processes, in Solar-Terrestrial Energy Programme: Major Scientific Problems, p. 52, University of Illinois Press, Urbana, 1988.
Siscoe, G. L., and T. S. Huang, Polar cap inflation and deflation, $J$. Geophys. Res., 90, 543, 1985.

Southwood, D. J., The ionospheric signature of flux transfer events, $J$. Geophys. Res., 92, 3207, 1987.

Southwood, D. J., Magnetopause coupling processes and ionospheric responses: A theoretical perspective, Philos. Trans. R. Soc. London, Ser. A, 328, 79, 1989.

Southwood, D. J., and W. J. Hughes, Theory of hydromagnetic waves in the magnetosphere, Space Sci. Rev., 35, 301, 1983.

Spence, H. E., M. G. Kivelson, and R. J. Walker, Comparison of fieldaligned currents at ionospheric and magnetospheric altitudes, $A d v$. Space Res., 8(9), 343, 1988.

Stem, D. P., A study of the electric field in an open magnetospheric model, J. Geophys. Res., 78, 7292, 1973.

Todd, H., S. W. H. Cowley, A. Etemadi, B. J. I. Bromage, M. Lockwood, D. M. Willis, and H. Luhr, Response time of the high-latitude ionosphere to sudden changes in the north-sout component of the IMF, Planel. Space Sci., 36, 1415, 1988 .

Todd, H., S. W. H. Cowley, A. Etemadi, B. J. I. Bromage, M. Lockwood, D. M. Willis, and H. Luhr, Flow in the high-latitude ionosphere: Measurements at 15s resolution made using the EISCAT "Polar" experiment, J. Atmos. Terr. Phys., 50, 423, 19886.

Toffoletto, F. R., and T. W. Hill, Mapping the solar wind electric field to the Earth's polar caps, J. Geophys. Res., 94, 329, 1989.

van Eyken, A. P., H. Rishbeth, D. M. Willis, and S. W. H. Cowley, Initial observations of plasma convection at invaraiant latitudes $70-77^{\circ}, \mathrm{J}$. Atmos. Terr. Phys., 46, 635, 1984.

Williams, D. J., D. G. Mitchell, T. E. Eastman, and L. A. Frank, Energetic particle observations in the low-latitude boundary layer, J. Geophys. Res., 90, 5097, 1985.

Williams, P. J. S., T. S. Virdi, and S. W. H. Cowley, Substorm processes in the geomagnetic tail and their effect in the nightside auroral zone ionosphere, as observed by EISCAT, Philos. Trans. R. Soc. London, Ser. A, 328, 137, 1989.

Willis, D. M., M. Lockwood, S. W. H. Cowley, A. P. van Eyken, B. J. I. Bromage, H. Rishbeth, P. R. Smith, and S.R. Crothers, A survey of simultaneous observations of the high-latitude ionosphere and interplanetary magnetic field with EISCAT and AMPTE-UKS, J. Atmos. Terr. Phys., 48, 987, 1986.

Wygant, J. R., R. B. Torbert, and F. S. Mozer, Comparison of S3-2 polar cap potential drops with the interplanetary magnetic field and models of magnetopause reconnection, J. Geophys. Res., 88, 5727, 1983.

S.W.H. Cowley and M.P. Freeman, Blackett Laboratory, Imperial College, London, SW7 2BZ, UK

M. Lockwood, Rutherford Appleton Laboratory, Chilton, Didcot, Oxon, OX11 OQX, UK
(Received January 3, 1989;

revised Sepiember 13, 1989;

accepted September 13, 1989.) 